\title{
The JUPITER study: statins for the primary prevention of cardiovascular events in patients with inflammatory rheumatic diseases?
}

\author{
Michael M Ward
}

Address: Intramural Research Program, National Institute of Arthritis and Musculoskeletal and Skin Diseases, National Institutes of Health, Bethesda, MD 20892, USA

Email: wardm1@mail.nih.gov

FI000 Medicine Reports 2009, I:35 (doi:10.34I0/MI-35)

The electronic version of this article is the complete one and can be found at: http://FI000.com/Reports/Medicine/content/I/35

\begin{abstract}
Patients with inflammatory rheumatic diseases have an increased risk of cardiovascular disease, raising questions of whether primary prevention strategies that are more aggressive than cardiac risk factor modification alone should be implemented. Recent trials demonstrating the efficacy of statins in reducing rates of cardiovascular events in healthy persons with elevated levels of C-reactive protein broaden the potential protective mechanisms of statins, but do not directly translate to primary cardiovascular disease prevention in patients with inflammatory rheumatic diseases.
\end{abstract}

\section{Introduction and context}

The risk of cardiovascular disease and cardiovascular mortality is increased in patients with inflammatory rheumatic diseases compared to the general population or to persons without these diseases. Although an increased risk is most well established for patients with systemic lupus erythematosus and rheumatoid arthritis, some evidence suggests an increased risk also exists for patients with ankylosing spondylitis, psoriasis, and psoriatic arthritis [1-5]. Although the reasons for this increased risk are not completely understood, the association between markers of inflammation, in particular, high-sensitivity C-reactive protein (hs-CRP), and cardiovascular risk in patients without known inflammatory disease has led to speculation that systemic inflammation itself may be etiologic [6-9]. Evidence that cardiovascular events are reduced in patients who respond to anti-inflammatory treatment supports this view [10].

\section{Recent advances}

The JUPITER study (Justification for the Use of Statins in Prevention: an Intervention Trial Evaluating Rosuvastatin) tested whether treatment with rosuvastatin altered the risk of incident cardiovascular events compared to placebo in persons with a normal level of low-density lipoprotein (LDL) cholesterol (less than $130 \mathrm{mg} / \mathrm{ml}$ ) but an elevated level of hs-CRP $(2.0 \mathrm{mg} / \mathrm{l}$ or higher) [11]. Persons with systemic inflammatory diseases, including severe arthritis and systemic lupus erythematosus, were excluded, as were those being treated with prednisone and other immunosuppressive medications. Subjects $(\mathrm{n}=17,802)$ were randomized to receive either $20 \mathrm{mg}$ rosuvastatin daily or placebo, for a planned duration of 5 years. The study's primary endpoint was the occurrence of a first major cardiovascular event, including myocardial infarction, stroke, hospitalization for unstable angina or arterial revascularization, or death from a cardiovascular cause.

The study was stopped prematurely when an interim analysis found that cardiovascular events were significantly less frequent in the group receiving rosuvastatin. The primary endpoint was $44 \%$ less likely in the rosuvastatin group than in the placebo group, although the rates of events were low in both groups. Reduced risks of similar magnitude were present for each condition comprising the primary endpoint. There was 
also a modest reduction in all-cause mortality in the rosuvastatin group. At 12 months, the median hs-CRP level was 37\% lower in the rosuvastatin group compared to placebo, from a baseline level of $2.2 \mathrm{mg} / \mathrm{l}$, and median LDL cholesterol was 50\% lower in the rosuvastatin group compared to placebo, from a baseline level of $186 \mathrm{mg} / \mathrm{dl}$.

These results indicate that treatment with rosuvastatin can decrease cardiovascular events among patients with an elevated hs-CRP level who do not have cholesterol levels elevated to the threshold customarily used to begin treatment. One possible implication of these results is that primary prevention strategies should be broadened to treat with statins those whose only cardiac risk factor is an elevated hs-CRP level. But is this an appropriate conclusion? Although subjects were selected based on both an elevated hs-CRP level and a normal LDL cholesterol level, the trial did not include a group with low hs-CRP levels and, therefore, did not isolate the benefit to patients with elevated hs-CRP levels specifically. Nor did it test hs-CRP as a screening tool to target treatment, which would have required a parallel arm of subjects who had not been tested for hs-CRP and were treated without regard to hs-CRP level. In the strictest interpretation, the JUPITER trial expands the potential mechanisms by which statins reduce cardiovascular events to include reductions in hs-CRP levels. Whether this effect is completely independent of the hypocholersterolemic effect is uncertain.

\section{Implications for clinical practice}

Given the elevated cardiovascular risk experienced by patients with inflammatory rheumatic diseases, and the association of elevated CRP levels with cardiovascular disease, how should the results of the JUPITER trial be applied to patients with inflammatory rheumatic diseases? If hs-CRP levels in persons without inflammatory diseases reflect inflammation in atherosclerotic endothelial lesions, while hs-CRP (or CRP) levels in patients with inflammatory diseases primarily reflect inflammation outside the atherosclerotic endothelial lesions, elevated hs-CRP levels would not be specific to the etiologic target in patients with inflammatory diseases. In this case, targeting treatment based on hs-CRP would not be helpful, and treatment might not be expected to have the same effects. Statins have multiple immunomodulatory actions, which may have a role in their cardioprotective effects [12]. Differences in activation or regulation of these immune and inflammatory pathways between patients with chronic inflammatory rheumatic diseases and people without these diseases complicate using the findings in non-rheumatic cohorts to predict effects in rheumatic disease cohorts. Also to be considered is whether any benefit of statins for primary prevention would be attenuated or negated by anti-rheumatic treatments, particularly chronic corticosteroids. Lastly, the long-term safety of statins and unknown risks of prolonged marked hypocholesterolemia would need to be balanced against the potential benefits.

Given the difficulty applying the results of the JUPITER trial to patients with inflammatory diseases, it would be premature to recommend statins for primary prevention of cardiovascular events in patients with inflammatory rheumatic diseases. Rather, cardiac risk factor assessment and modification should be enforced, while awaiting the results of ongoing or recently completed studies specifically investigating statins for primary cardiovascular disease prevention in systemic lupus erythematosus and rheumatoid arthritis [13-15].

\section{Abbreviations}

hs-CRP, high-sensitivity C-reactive protein; JUPITER, Justification for the Use of Statins in Prevention: an Intervention Trial Evaluating Rosuvastatin; LDL, lowdensity lipoprotein.

\section{Competing interests}

The author declares that he has no competing interests.

\section{Acknowledgements}

Supported by the Intramural Research Program, National Institute of Arthritis and Musculoskeletal and Skin Diseases and National Institutes of Health.

\section{References}

I. Westerweel PE, Luyten RK, Koomans HA, Derksen RH, Verhaar MC: Premature atherosclerotic cardiovascular disease in systemic lupus erythematosus. Arthritis Rheum 2007, 56:I384-96.

2. Boers M, Dijkmans B, Gabriel S, Maradit-Kremers H, O'Dell J, Pincus T: Making an impact on mortality in rheumatoid arthritis. Targeting cardiovascular comorbidity. Arthritis Rheum 2004, 50: 1734-9.

3. Solomon DH, Goodson NJ, Katz JN, Weinblatt ME, Avorn J, Setoguchi S, Canning C, Schneeweiss S: Patterns of cardiovascular risk in rheumatoid arthritis. Ann Rheum Dis 2006, 65:1608-I2.

4. Han C, Robinson DW Jr, Hackett MV, Paramore LC, Fraeman KH, Bala MV: Cardiovascular disease and risk factors in patients with rheumatoid arthritis psoriatic arthritis and ankylosing spondylitis. J Rheumatol 2006, 33:2167-72.

5. Gelfand JM, Neimann AL, Shin DB, Wang X, Margolis DJ, Troxel AB: Risk of myocardial infarction in patients with psoriasis. JAMA 2006, 296:|735-4|.

6. Pai JK, Pischon T, Ma J, Manson JE, Hankinson SE, Joshipura K, Curhan GC, Rifai N, Cannuscio CC, Stampfer MJ, Rimm EB: Inflammatory markers and the risk of coronary heart disease in men and women. N Engl J Med 2004, 351:2599-610.

7. Ridker PM, Cushman M, Stampfer MJ, Tracy RP, Hennekens $\mathrm{CH}$ : Inflammation, aspirin, and the risk of cardiovascular disease in apparently healthy men. N Engl J Med 1997, 336:973-9.

8. Yeh ET: CRP as a mediator of disease. Circulation 2004, 109 (Suppl II):II-I I-I4. 
9. Maradit-Kremers H, Nicola PJ, Crowson CS, Ballman KV, Gabriel SE: Cardiovascular death in rheumatoid arthritis. A populationbased study. Arthritis Rheum 2005, 52:722-32.

10. Dixon WG, Watson KD, Lunt M, Hyrich KLBritish Society for Rheumatology Biologics Register Control Centre Consortium, Silman AJ, Symmons DPM: Reduction in the incidence of myocardial infarction in patients with rheumatoid arthritis who respond to anti-tumor necrosis factor $\alpha$ therapy. Results from the British Society for Rheumatology Biologics Register. Arthritis Rheum 2007, 56:2905-12.

II. Ridker PM, Danielson E, Fonseca FAH, Genest J, Gotto AMJr, Kastelein JJP, Koenig W, Libby P, Lorenzatti A], MacFadyen JG, Nordestgaard BG, Shepherd J, Willerson JT, Glynn RJ; JUPITER Study Group: Rosuvastatin to prevent vascular events in men and women with elevated C-reactive protein. $N$ Engl J Med 2008, 359:2195-207.

Changes Clinical Practice

FI000 Factor 9.9 Exceptional

Evaluated by Melvin Cheitlin 28 Nov 2008, Seth Field 09 Feb 2009,

Judy Kersten 26 Mar 2009, Conrado Estol 30 Mar 2009
12. Schönbeck U, Libby P: Inflammation, immunity, and HMG-CoA reductase inhibitors statins as anti-inflammatory agents? Circulation 2004, 109(2I SuppI I):III8-26.

13. Petri M, Kiani AN, Post W, Magder L: Lupus Atherosclerosis Prevention Study (LAPS): a randomized double blind placebo controlled trial of atorvastatin versus placebo. Arthritis Rheum 2006, 54(Suppl):S520.

14. Schanberg LE, Sandborg C: Dyslipoproteinemia and premature atherosclerosis in pediatric systemic lupus erythematosus. Curr Rheumatol Rep 2004, 6:425-33.

15. Urowitz MB, Gladman D, Ibañez D, Fortin P, Sanchez-Guerrero J, Bae S, Clarke A, Bernatsky S, Gordon C, Hanly J, Wallace D, Isenberg D, Ginzler E, Merrill J, Alarcón GS, Steinsson K, Petri M, Dooley MA, Bruce I, Manzi S, Khamashta M, Ramsey-Goldman R, Zoma A, Sturfelt G, Nived O, Maddison P, Font J, van Vollenhoven R, Aranow C, Kalunian K, et al.: Systemic Lupus International Collaborating Clinics: Accumulation of coronary artery disease risk factors over three years: data from an international inception cohort. Arthritis Rheum 2008, 59:176-80. 